\title{
The Severity of Ischemia Determines and Predicts Malignant Brain Edema in Patients with Large Middle Cerebral Artery Infarction
}

\author{
Christian Dohmen ${ }^{\mathrm{a}, \mathrm{b}}$ Norbert Galldiks ${ }^{\mathrm{b}, \mathrm{d}}$ Bert Bosche ${ }^{\mathrm{a}, \mathrm{c}}$ Lutz Kracht ${ }^{\mathrm{a}}$ \\ Rudolf Graf ${ }^{a}$ \\ ${ }^{a}$ Max Planck Institute for Neurological Research, and Departments of ${ }^{b}$ Neurology and ${ }^{c}$ Neurosurgery, \\ University of Cologne, Cologne, ${ }^{d}$ Institute of Neuroscience and Medicine (INM-3), Research Centre Jülich, \\ Jülich, Germany
}

\section{Key Words}

Brain edema • Ischemic stroke • Malignant infarction •

Emission tomography

\begin{abstract}
Background: In order to determine the impact of the severity of ischemia on malignant edema formation, we investigated various degrees of perfusional deficit by ${ }^{11} \mathrm{C}$-flumazenil PET in patients with large middle cerebral artery (MCA) infarction. Methods: 17 patients with large MCA stroke were included. Cerebral blood flow (CBF) was measured $15.9 \pm$ $6.4 \mathrm{~h}$ after the ictus. Patients were divided into a malignant $(n=9)$ and a benign group $(n=8)$ as a function of their clinical courses and edema. Edema was measured as maximal midline shift on follow-up CTs. Total hypoperfusion volume was divided into different subvolumes according to the degree of CBF reduction. Results: Subvolumes of severe ischemia relative to total ischemic area were significantly larger in the malignant group than in the benign group and were significantly correlated with edema formation. The highest correlation and best predictive values for edema formation with a sensitivity, specificity, and a positive and negative predictive value of $100 \%$ were found for subvolumes with severe ischemia. Correlation coefficients and prediction de-
\end{abstract}

\section{KARGER}

Fax +41613061234 E-Mail karger@karger.ch www.karger.com

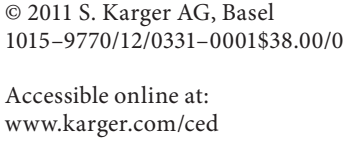

creased for subvolumes with less severe perfusional deficit, pointing to the risk of misclassifying patients when relying on the volume of total perfusional deficit alone. Conclusions: Malignant MCA infarction seems to be determined more by the volume of severe perfusional deficit than that of total perfusional deficit. Assessment of severely ischemic areas allows prediction of malignant edema formation and might help to select candidates for hemicraniectomy.

Copyright $\odot 2011$ S. Karger AG, Basel

\section{Introduction}

Space-occupying brain edema is a life-threatening complication after a large middle cerebral artery (MCA) infarction. Such a clinical course carries a mortality risk of up to $80 \%$ under conservative treatment in early retrospective studies and has therefore been termed 'malignant' MCA infarction [1]. Recently, randomized controlled clinical trials have confirmed a high mortality rate of $>70 \%$ under conservative treatment and have

\section{C.D., N.G., and B.B. contributed equally to this work.}

Dr. Christian Dohmen

Department of Neurology, University Hospital of Cologne

Kerpenerstrasse 62

DE-50924 Cologne (Germany)

Tel. +49 221478 4015, E-Mail christian.dohmen@uk-koeln.de 
shown decompressive hemicraniectomy to significantly reduce mortality and morbidity when performed within the first $48 \mathrm{~h}$ after stroke [2-4]. Since maximal edema formation is reached only $2-5$ days after MCA infarction, the life-saving effect of hemicraniectomy seems to depend on early implementation, i.e. before massive brain edema has developed [5]. Thus, space-occupying brain edema has to be anticipated to reasonably implement hemicraniectomy. However, the pathophysiology of edema formation after an MCA infarction in humans is still poorly understood, and it is difficult to predict a malignant clinical course in individual patients. Several attempts have been made to find predictors of life-threatening brain edema after an MCA infarction [for a review, see ref. 6]. So far, infarct size is assumed to be the major determinant of space-occupying brain edema as shown in several clinical studies with different imaging modalities [7-10]. However, positive and negative predictive values of this radiological variable for life-threatening brain edema were too low to be used as a sole predictor for the selection of candidates for prophylactic hemicraniectomy [6]. Thus, other parameters than infarct size are presumably involved in the pathophysiology of postischemic edema formation. It has been shown experimentally that the magnitude of edema formation following ischemia depends on the severity of the decrease in cerebral blood flow (CBF), pointing to a functional and structural breakdown of the blood-brain barrier when CBF is severely suppressed [11-15]. In patients with large MCA infarctions, the extent and distribution of different grades of ischemia and their impact on subsequent edema formation have not yet been investigated. In the present study, we measured CBF semiquantitatively with ${ }^{11} \mathrm{C}$ flumazenil (FMZ) PET $\left(\mathrm{CBF}_{\mathrm{FMZ}}\right)$ in such patients [16] and analyzed compartments with different grades of ischemia in order to predict space-occupying edema formation.

\section{Patients and Methods}

This study was approved by the Ethics Committee of the Medical Faculty of the University of Cologne. We included 17 patients suffering from a clinically severe ischemic MCA syndrome and hypoattenuation on early $(<12 \mathrm{~h})$ CT scans exceeding $>50 \%$ of the MCA territory. Patients with initial involvement of additional vascular territories and patients with space-occupying hemorrhage were excluded from the study. Patients were divided post hoc into a malignant group and a benign group according to the clinical course and extent of brain edema on the CT scan. Courses were regarded as malignant when the patients had clinical signs of uncal herniation with a further decrease in consciousness and a unilaterally fixed and dilated pupil and/or if the patients developed a space-occupying brain edema with a midline shift $>5 \mathrm{~mm}$ at the level of the septum pellucidum on a follow-up CT. Two of 17 patients underwent hemicraniectomy and showed clinical signs of herniation before decompressive surgery was performed. In these 2 patients PET scans were performed before hemicraniectomy. All patients were admitted to the neurological intensive care unit and underwent antiedematous therapy, including $30^{\circ}$ elevation of the upper body and osmotic therapy with mannitol. Serial native CT scans were performed on admission, at 6-12 h, at days 2-5 and additional scans were performed if patients showed signs of clinical deterioration. The extent of edema formation was measured as a maximal midline shift on follow-up CTs at the level of the septum pellucidum. Extracranial and transcranial Doppler sonography was performed on admission and 12-24 h thereafter. Neurological deficits were assessed with the modified Rankin Scale (mRS) after 3 months.

\section{Positron Emission Tomography}

PET studies were performed on an ECAT EXACT HR scanner (Siemens CTI) [17]. PET data were analyzed by researchers blinded to clinical data (N.G., L.K.). Twenty millicuries (740 $\mathrm{MBq}$ ) of FMZ was injected intravenously. Early tracer distribution within 2 min after injection allowed measurement of regional $\mathrm{CBF}$ without arterial input function $\left(\mathrm{CBF}_{\mathrm{FMZ}}\right)$ [16]. A reduction in FMZ distribution of $<70 \%$ of the average distribution within the contralateral hemisphere has been shown to correspond to an absolute CBF of approximately $<20 \mathrm{ml} \cdot 100$ $\mathrm{g}^{-1} \cdot \mathrm{min}^{-1}$. We have therefore used this threshold to define total volume of hypoperfusion. Within this total volume, subvolumes were defined using the following $\mathrm{CBF}_{\mathrm{FMZ}}$ reductions $<70,<60$, $<50,<40,<30,<20$ and $<10 \%$ compared to the average distribution within the contralateral hemisphere. These percent reductions have been shown to correspond to absolute $\mathrm{CBF}$ values of approximately $<20,<18,<14,<12,<8,<6$ and $<4 \mathrm{ml} \cdot 100$ $\mathrm{g}^{-1} \cdot \mathrm{min}^{-1}$, respectively [16]. From the 17 patients presented in this study, we have included FMZ PET data from 8 patients, who were partly analyzed and presented before [10]. In that previous study, we reported on FMZ binding and CBF within the ischemic core from those 8 patients who we have now analyzed, and present for the first time, a detailed and systematic analysis of the extent and distribution of different grades of ischemia and their impact on subsequent edema formation.

\section{Statistical Analysis}

The results are expressed as means \pm SD unless otherwise noted. Pearson's correlation coefficient was used to analyze correlations between the volume of ischemic subvolumes (cubic centimeters) and midline shift (millimeters). Comparisons between patient groups were analyzed by Student's t test or the Mann-Whitney $\mathrm{U}$ test for quantitative variables as appropriate - by the MannWhitney U test for ordinal variables, and by the $\chi^{2}$ test for categorical variables. Significance levels were chosen as $\mathrm{p}<0.05$ and $\mathrm{p}<$ 0.005 (n.s. = not significant). To define a threshold (cut-off value) with optimal diagnostic accuracy for differenting among groups, we determined the receiver-operated characteristic curve (ROC). Statistical analysis was performed with a commercial software package (SPSS for Windows, version 17.0, SPSS UK). 


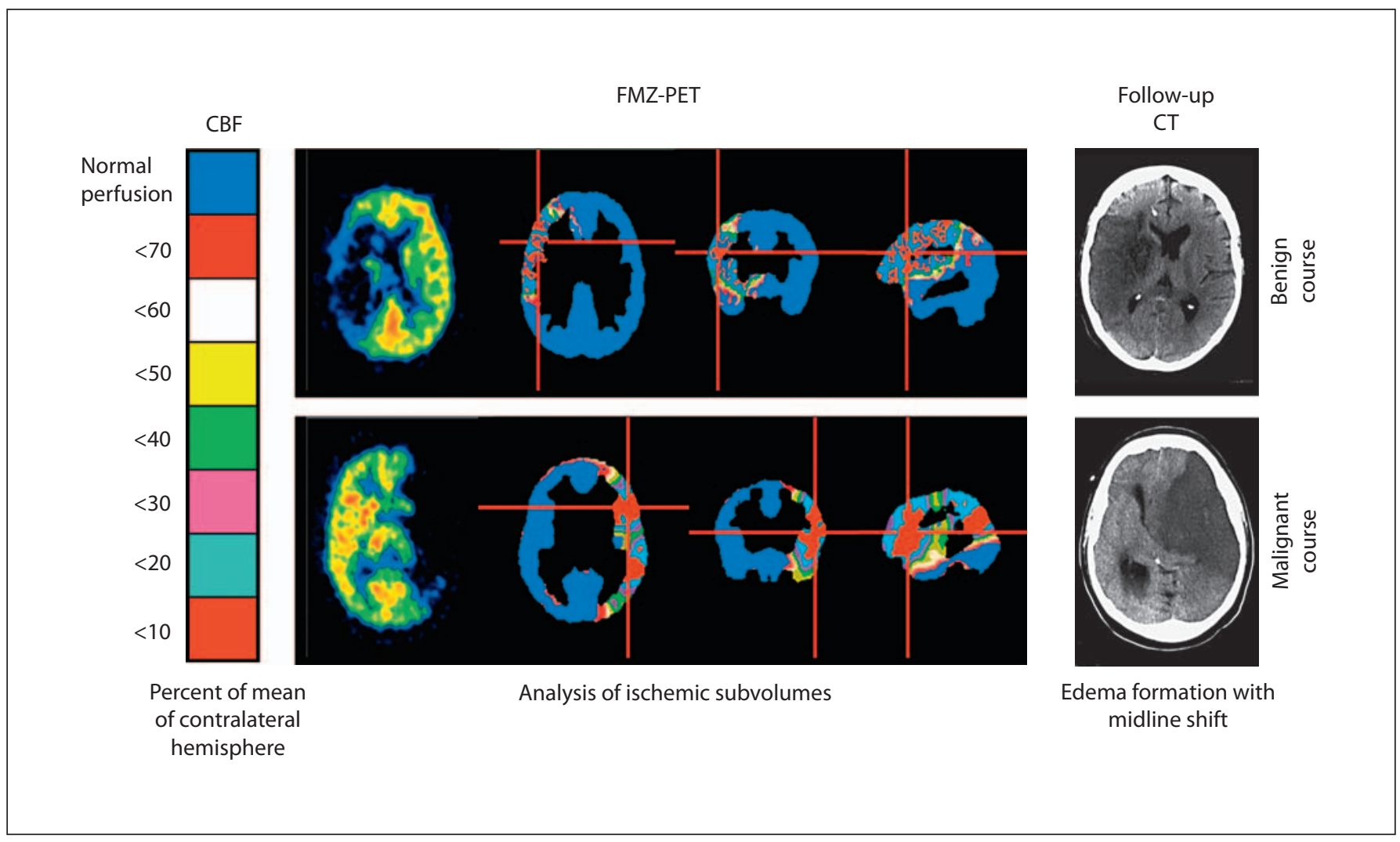

Fig. 1. Analysis of ischemic subvolumes by ${ }^{11} \mathrm{C}$-flumazenil PET $\left(\mathrm{CBF}_{\mathrm{FMZ}}\right)$ : the total volume of hypoperfusion was defined as a $\mathrm{CBF}<70 \%$ of the mean of the contralateral hemisphere, which approximately corresponds to $<20 \mathrm{ml} / \mathrm{min} / 100 \mathrm{~g}$ [16]. The total volume of hypoperfusion was then divided into several ischemic subvolumes applying different ischemic thresholds to assess the size of the various subvolumes. Maximal edema formation was assessed as a midline shift on the follow-up CT. Patients were divided into a benign and a malignant group according to the clinical course and extent of edema formation.

\section{Results}

Nine of 17 patients developed malignant courses. Four patients with malignant courses died as a result of transtentorial herniation, 2 patients underwent hemicraniectomy and survived. All surviving patients of the malignant group had moderate to severe neurological defects. The 8 patients with benign courses did not develop malignant brain swelling and survived with moderate to severe neurological handicaps. Overall, patients with malignant courses showed larger maximal midline shifts, more severe neurological deficits, i.e. higher mRS scores and the left hemisphere was affected more often compared to patients with benign courses (table 1).

PET was performed within 3-24 h (15.9 $\pm 6.4 \mathrm{~h})$ after the ictus (malignant group: $15.2 \pm 7.1$, benign group: $16.4 \pm 6.3, p=$ n.s.). To exemplify measurement of isch-
Table 1. Characteristics of patients with malignant versus benign courses

\begin{tabular}{lccc}
\hline Patient characteristics & $\begin{array}{l}\text { Malignant } \\
(\mathrm{n}=9)\end{array}$ & $\begin{array}{l}\text { Benign } \\
(\mathrm{n}=8)\end{array}$ & $\mathrm{p}$ \\
\hline Mean age, years & $54.6 \pm 6.5$ & $58.9 \pm 8.7$ & n.s. ${ }^{1}$ \\
Sex, M/F, n & $6 / 3(67 / 33)$ & $4 / 4(50 / 50)$ & n.s. ${ }^{2}$ \\
Hemisphere, right/left, $\mathrm{n}$ & $3 / 6(33 / 66)$ & $6 / 2(75 / 25)$ & $<0.005^{2}$ \\
Thrombolysis, $\mathrm{n}$ & $3(33)$ & $3(38)$ & n.s. $^{2}$ \\
Initial occlusion of MCA, n & $8(89)$ & $6(75)$ & n.s. ${ }^{2}$ \\
Reperfusion of MCA, n & $1(11)$ & $1(13)$ & n.s. ${ }^{2}$ \\
Maximal midline shift, n & $12.6 \pm 7.1$ & $3.6 \pm 2.0$ & $<0.005^{1}$ \\
mRS & $3.5(3-5)^{3}$ & $5.0(3-6)^{3}$ & $<0.05^{4}$ \\
\hline
\end{tabular}

Figures in parentheses are percentages.

${ }^{1}$ Student's t test. ${ }^{2} \chi^{2}$ test. ${ }^{3}$ Range of mRS. ${ }^{4}$ Mann-Whitney U test.

Cerebrovasc Dis 2012;33:1-7 
Table 2. Comparison of ischemic subvolumes between the two outcome groups in absolute and relative terms

\begin{tabular}{|c|c|c|c|c|c|c|}
\hline \multirow{2}{*}{$\begin{array}{l}\text { CBF reduction } \\
\text { mean percent of } \\
\text { contralateral } \\
\text { hemisphere }\end{array}$} & \multicolumn{2}{|c|}{ Absolute volumes $\mathrm{cm}^{3}$} & \multirow[t]{2}{*}{$\mathrm{p}$} & \multicolumn{2}{|c|}{$\begin{array}{l}\text { Relative volumes in relation to total } \\
\text { perfusional deficit }\end{array}$} & \multirow[t]{2}{*}{$\mathrm{p}$} \\
\hline & malignant group & benign group & & malignant group & benign group & \\
\hline $\mathrm{CBF}<70 \%$ & $188.5 \pm 36.9$ & $106.6 \pm 53.1$ & $<0.005^{\mathrm{a}}$ & 1.0 & 1.0 & n.s. ${ }^{b}$ \\
\hline $\mathrm{CBF}<60 \%$ & $163.1 \pm 30.1$ & $76.6 \pm 41.1$ & $<0.005^{\mathrm{a}}$ & $0.87 \pm 0.03$ & $0.68 \pm 0.13$ & $<0.005^{\mathrm{b}}$ \\
\hline $\mathrm{CBF}<50 \%$ & $149.8 \pm 24.9$ & $51.5 \pm 35.8$ & $<0.005^{\mathrm{a}}$ & $0.77 \pm 0.06$ & $0.42 \pm 0.16$ & $<0.005^{\mathrm{b}}$ \\
\hline $\mathrm{CBF}<40 \%$ & $130.3 \pm 24.9$ & $33.6 \pm 31.7$ & $<0.005^{\mathrm{a}}$ & $0.66 \pm 0.08$ & $0.23 \pm 0.15$ & $<0.005^{\mathrm{b}}$ \\
\hline $\mathrm{CBF}<30 \%$ & $110.2 \pm 26.9$ & $21.0 \pm 27.0$ & $<0.005^{\mathrm{a}}$ & $0.56 \pm 0.10$ & $0.12 \pm 0.13$ & $<0.005^{\mathrm{b}}$ \\
\hline $\mathrm{CBF}<20 \%$ & $83.1 \pm 29.8$ & $15.0 \pm 26.1$ & $<0.005^{\mathrm{b}}$ & $0.43 \pm 0.12$ & $0.06 \pm 0.09$ & $<0.005^{\mathrm{b}}$ \\
\hline $\mathrm{CBF}<10 \%$ & $40.4 \pm 25.7$ & $5.2 \pm 8.9$ & $<0.005^{\mathrm{b}}$ & $0.20 \pm 0.11$ & $0.02 \pm 0.04$ & $<0.005^{\mathrm{b}}$ \\
\hline
\end{tabular}

a Student's t test. ${ }^{\mathrm{b}}$ Mann-Whitney U test.

Table 3. Predictive values of the ischemic subvolumes and correlation with edema formation

\begin{tabular}{|c|c|c|c|c|c|c|c|}
\hline \multirow[t]{2}{*}{$\begin{array}{l}\text { Ischemic } \\
\text { subvolume }\end{array}$} & \multicolumn{2}{|c|}{$\begin{array}{l}\text { Correlation with edema } \\
\mathrm{mm} \text { midline shift }\end{array}$} & \multirow[t]{2}{*}{$\begin{array}{l}\text { Cut-off value } \\
\mathrm{cm}^{3}\end{array}$} & \multirow[t]{2}{*}{$\begin{array}{l}\text { Sensitivity } \\
\%\end{array}$} & \multirow[t]{2}{*}{$\begin{array}{l}\text { Specificity } \\
\%\end{array}$} & \multirow[t]{2}{*}{$\begin{array}{l}\text { PPV } \\
\%\end{array}$} & \multirow[t]{2}{*}{$\begin{array}{l}\text { NPV } \\
\%\end{array}$} \\
\hline & $\mathrm{r}$ & $\mathrm{p}^{1}$ & & & & & \\
\hline$<10 \%$ & 0.84 & $<0.005$ & 13 & 100 & 100 & 100 & 100 \\
\hline$<20 \%$ & 0.82 & $<0.005$ & 37 & 100 & 100 & 100 & 100 \\
\hline$<30 \%$ & 0.77 & $<0.005$ & 58 & 100 & 100 & 100 & 100 \\
\hline$<40 \%$ & 0.75 & $<0.005$ & 80 & 100 & 100 & 100 & 100 \\
\hline$<50 \%$ & 0.72 & $<0.005$ & 103 & 100 & 100 & 100 & 100 \\
\hline$<60 \%$ & 0.65 & $<0.05$ & 115 & 100 & 87.5 & 90 & 100 \\
\hline$<70 \%$ & 0.58 & n.s. & 136 & 100 & 75 & 81.8 & 100 \\
\hline
\end{tabular}

${ }^{1}$ Student's t test.

emic subvolumes by FMZ PET, data sets from a patient with a benign and a patient with malignant course are shown in figure 1 . Total volume of hypoperfusion $(<70 \%$ of the mean of the contralateral hemisphere) was larger in the malignant group compared to the benign group (table 2). However, the specificity and positive predictive value for predicting malignant brain edema was relatively low (75 and $81.8 \%$, respectively) when relying on the total volume of hypoperfusion alone (cut-off: 136 $\mathrm{cm}^{3}$, table 3). This was due to the fact that in several patients of the benign group, total volume of hypoperfusion was larger than in some patients with malignant clinical courses, thus decreasing the discriminatory power of this predictor when relying on total volume. Also, the correlation with the extent of edema formation (maximal midline shift on CT, $\mathrm{mm}$ ) was weak, with $\mathrm{r}=$
0.58 ( $\mathrm{p}=$ n.s., table 3 ). Mean volumes of severe ischemia relative to total ischemic volume were larger in the malignant group than in the benign group (fig. 2a, table 2). Ischemic subvolumes with extreme reduction of perfusion $<10 \%$, for example, amounted to $20 \%$ of the total volume of hypoperfusion in the malignant group and to only $2 \%$ in the benign group. Moreover, in the malignant group, the volume of deep to moderate CBF reduction $(<30 \%$, table 2$)$ amounted to more than half $(56 \%)$ of the total volume with hypoperfusion compared to the benign group, with only $12 \%$ of the total hypoperfused volume. This difference between the two groups regarding the distribution of the various subvolumes of ischemic transformation holds true even if absolute values are compared. Figure $2 \mathrm{~b}$ shows examples of a patient with a benign course and a patient with a malignant 
Fig. 2. a Mean of the various ischemic subvolumes in relation to total hypoperfusion volume (defined as $<70 \%$ of the mean of the contralateral hemisphere). Note the greater proportion of severely ischemic tissue in the malignant group compared to the bening group. $\mathbf{b}$ The distribution of various ischemic subvolumes is exemplified in 2 patients with comparable size of total hypoperfusion. The patient who later developed malignant brain edema shows severe CBF reduction below $30 \%$ of the control value in more than half of the ischemic territory, whereas in the patient without subsequent space-occupying edema only a small proportion of the ischemic territory displays such a drastically diminished $\mathrm{CBF}$.

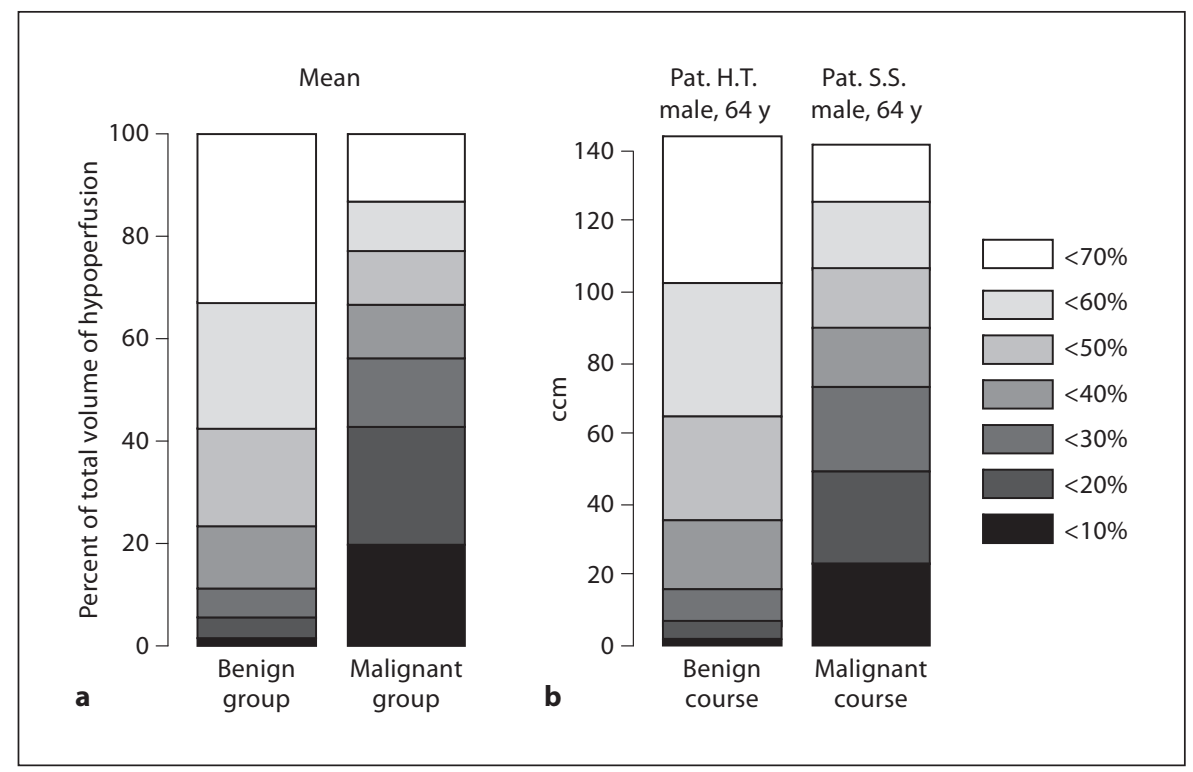

course. In these examples, total volume of hypoperfusion, but also age (both patients were 64 years old) and neurological deficit (NIHSS, benign: 19, malignant: 18) were matched. Severely ischemic volumes were large in the patient with a malignant course and, in contrast, mildly ischemic volumes were the largest in the patient with a benign course. Ischemic volumes calculated for $<10$ to $<50 \%$ reductions in CBF showed excellent correlations with the midline shift in CT. The best correlation was found for an ischemic volume $<10 \%$ (table 3 ), and the coefficients decreased for volumes with higher thresholds. The maximal midline shift was reached at a mean of $58.4 \mathrm{~h}$ after stroke (benign group: $62.4 \pm$ $16.9 \mathrm{~h}$; malignant group: $54.7 \pm 19.7 \mathrm{~h}, \mathrm{p}=\mathrm{n} . \mathrm{s}$.) and ranged from 0 to $24.9 \mathrm{~mm}$ (benign group: $3.6 \pm 2.0 \mathrm{~mm}$; malignant group: $12.6 \pm 7.1 \mathrm{~mm}, \mathrm{p}<0.005)$. Sensitivity, specificity, positive predictive value and negative predictive value for predicting brain edema were $100 \%$, respectively, for volumes with severe ischemia, with decreasing specificity and positive predictive value for volumes $<60$ and $<70 \%$ CBF reduction (table 3 ).

\section{Discussion}

Thomalla et al. [18] have recently shown that a lesion of $>82 \mathrm{ml}$ within the first $6 \mathrm{~h}$ after stroke on diffusionweighted MRI predicted a malignant course with high specificity and a positive predictive value, but the sensi- tivity was low and more than half of the patients with malignant courses were missed when relying on this parameter. The total size of the perfusion deficit has been suggested to be a useful predictor of a malignant course as well, but the results from previous clinical studies are controversial and again predictive values were low in most studies [18-21]. In the present study, the mean volume of total perfusion deficit was larger in the patients who eventually developed space-occupying malignant brain edema than in the group with a benign clinical course. It should be considered, however, that in several patients with benign courses the volume of total perfusion deficit was larger than in patients with malignant courses, thus decreasing the discriminatory power of this predictor, which is reflected by the low specificity and positive predictive value when relying on the volume of total perfusion deficit alone. This points to the risk of misclassifying patients when relying on the volume of total perfusion deficit and might explain the finding of Thomalla et al. [18] that the perfusion lesion in MRI defined by time to peak $>4 \mathrm{~s}$ was predictive of malignant MCA infarction in univariate analysis, but did not turn out to be an independent predictor. In contrast, we found high sensitivity, high specificity and high predictive values for predicting a malignant course when patients were discriminated by the volume of severely reduced CBF. Thus, determining the volume of severe ischemic transformation measured by $\mathrm{CBF}_{\mathrm{FMZ}}$ allows reliable prediction of malignant MCA infarction within the time win- 
dow in which hemicraniectomy has been shown to be most effective, i.e. within $24-48 \mathrm{~h}$ after stroke [2-5]. With $100 \%$ sensitivity, specificity, positive predictive value and a negative predictive value for areas of severely reduced $\mathrm{CBF}$, this parameter, to the best of our best knowledge, enables the most precise prediction of malignant MCA infarction published so far. Also, the correlation with space-occupying edema formation was the best for those regions of very severe ischemia. These results suggest that the extent of space-occupying edema after MCA infarction mainly depends on the severity of ischemia. In accordance with experimental results [11-15], a recent clinical study using MRI permeability imaging has suggested blood-brain barrier (BBB) permeability disorders to be associated with malignant MCA infarction [22], and Serena et al. [23] have found molecular markers of BBB damage to be increased in the serum of patients who later developed malignant MCA infarction. In view of these surrogate parameters for $\mathrm{BBB}$ damage in patients with malignant MCA infarction and the results of the present study, we speculate that large areas of severe ischemia after MCA infarction lead to a substantial damage to the $\mathrm{BBB}$, which in turn triggers the formation of vasogenic brain edema. Considering previous clinical studies and the results of the present study, we assume that development of space-occupying brain edema after MCA infarc- tion is a function of both, size and severity of ischemia. Several limitations of our study have to be considered: with 17 patients included, the sample size is small (although relatively high for a PET study in stroke) and our findings have not yet been validated in a larger independent sample. Due to the small number of patients, we could not correct for multiple comparisons and can thus not exclude confounders. Our aim was a first descriptive analysis in a small sample in order to detect a possible predictor of a malignant course by detailed analysis of the perfusional deficit. Since PET is not often used in the clinical routine, it would be of particular interest if our results could be confirmed by the imaging tools routinely used in acute stroke diagnosis, such as perfusion MRI or perfusion CT.

\section{Acknowledgement}

This study was supported by the Federal Ministry of Education and Research (BMBF), Competence Network Stroke.

\section{Disclosure Statement}

There are no conflicts of interest and no disclosures.

\section{References}

1 Hacke W, Schwab S, Horn M, Spranger M, De Georgia M, von Kummer R: 'Malignant' middle cerebral artery territory infarction: clinical course and prognostic signs. Arch Neurol 1996;53:309-315.

-2 Juttler E, Schwab S, Schmiedek P, Unterberg A, Hennerici M, Woitzik J, Witte S, Jenetzky E, Hacke W: Decompressive Surgery for the Treatment of Malignant Infarction of the Middle Cerebral Artery (DESTINY): a randomized, controlled trial. Stroke 2007;38: 2518-2525.

3 Hofmeijer J, Kappelle LJ, Algra A, Amelink GJ, van Gijn J, van der Worp HB: Surgical decompression for space-occupying cerebral infarction (the Hemicraniectomy after Middle Cerebral Artery Infarction with LifeThreatening Edema Trial [HAMLET]): a multicentre, open, randomised trial. Lancet Neurol 2009;8:326-333.

4 Vahedi K, Hofmeijer J, Juettler E, Vicaut E, George B, Algra A, Amelink GJ, Schmiedeck P, Schwab S, Rothwell PM, Bousser MG, van der Worp HB, Hacke W: Early decompressive surgery in malignant infarction of the middle cerebral artery: a pooled analysis of three randomised controlled trials. Lancet Neurol 2007;6:215-222.

5 Schwab S, Steiner T, Aschoff A, Schwarz S, Steiner HH, Jansen O, Hacke W: Early hemicraniectomy in patients with complete middle cerebral artery infarction. Stroke 1998; 29:1888-1893.

6 Hofmeijer J, Algra A, Kappelle LJ, van der Worp HB: Predictors of life-threatening brain edema in middle cerebral artery infarction. Cerebrovasc Dis 2008;25:176-184.

7 Oppenheim C, Samson Y, Manai R, Lalam T, Vandamme X, Crozier S, Srour A, Cornu P Dormont D, Rancurel G, Marsault C: Prediction of malignant middle cerebral artery infarction by diffusion-weighted imaging. Stroke 2000;31:2175-2181.

$>8$ von Kummer R, Meyding-Lamade U, Forsting M, Rosin L, Rieke K, Hacke W, Sartor K: Sensitivity and prognostic value of early CT in occlusion of the middle cerebral artery trunk. AJNR Am J Neuroradiol 1994;15:915; discussion 16-18.

$\checkmark 9$ Kasner SE, Demchuk AM, Berrouschot J, Schmutzhard E, Harms L, Verro P, Chalela JA, Abbur R, McGrade H, Christou I, Krie- ger DW: Predictors of fatal brain edema in massive hemispheric ischemic stroke. Stroke 2001;32:2117-2123.

10 Dohmen C, Bosche B, Graf R, Staub F, Kracht L, Sobesky J, Neveling M, Brinker G, Heiss WD: Prediction of malignant course in MCA infarction by PET and microdialysis. Stroke 2003;34:2152-2158.

11 Symon L, Branston NM, Chikovani O: Ischemic brain edema following middle cerebral artery occlusion in baboons: relationship between regional cerebral water content and blood flow at 1 to 2 hours. Stroke 1979;10: 184-191.

12 Iannotti F, Hoff J: Ischemic brain edema with and without reperfusion: an experimental study in gerbils. Stroke 1983;14:562-567.

13 Crockard A, Iannotti F, Hunstock AT, Smith RD, Harris RJ, Symon L: Cerebral blood flow and edema following carotid occlusion in the gerbil. Stroke 1980;11:494-498.

$>14$ Bell BA, Symon L, Branston NM: CBF and time thresholds for the formation of ischemic cerebral edema, and effect of reperfusion in baboons. J Neurosurg 1985;62:3141 . 
15 Ayata C, Ropper AH: Ischaemic brain oedema. J Clin Neurosci 2002;9:113-124.

-16 Thiel A, Lottgen J, Grond M, Pietrzyk U, Heiss WD: Estimation of regional cerebral blood flow levels in ischemia using $\left[{ }^{15} \mathrm{O}\right]$ water of $\left[{ }^{11} \mathrm{C}\right]$ flumazenil PET without arterial input function. J Comput Assist Tomogr 2001;25:446-451.

-17 Wienhard K, Dahlbom M, Eriksson L, Michel C, Bruckbauer T, Pietrzyk U, Heiss WD: The ECAT EXACT HR: performance of a new high resolution positron scanner. J Comput Assist Tomogr 1994;18:110-118.
8 Thomalla G, Hartmann F, Juettler E, Singer OC, Lehnhardt FG, Köhrmann M, Kersten JF, Krützelmann A, Humpich MC, Sobesky J, Gerloff C, Villringer A, Fiehler J, Neumann-Haefelin T, Schellinger PD, Röther J; Clinical Trial Net of the German Competence Network Stroke: Prediction of malignant middle cerebral artery infarction by magnetic resonance imaging within 6 hours of symptom onset: a prospective multicenter observational study. Ann Neurol 2010;68: 435-445.

19 Dittrich R, Kloska SP, Fischer T, Nam E, Ritter MA, Seidensticker P, Heindel W, Nabavi DG, Ringelstein EB: Accuracy of perfusion$\mathrm{CT}$ in predicting malignant middle cerebral artery brain infarction. J Neurol 2008;255: 896-902.

20 Berrouschot J, Barthel H, von Kummer R, Knapp WH, Hesse S, Schneider D: 99m technetium-ethyl-cysteinate-dimer single-photon emission ct can predict fatal ischemic brain edema. Stroke 1998;29:2556-2562.
21 Firlik AD, Yonas H, Kaufmann AM, Wechsler LR, Jungreis CA, Fukui MB, Williams RL: Relationship between cerebral blood flow and the development of swelling and life-threatening herniation in acute ischemic stroke. J Neurosurg 1998;89:243249.

22 Bang OY, Saver JL, Alger JR, Shah SH, Buck BH, Starkman S, Ovbiagele B, Liebeskind DS: Patterns and predictors of blood-brain barrier permeability derangements in acute ischemic stroke. Stroke 2009;40:454-461.

23 Serena J, Blanco M, Castellanos M, Silva Y, Vivancos J, Moro MA, Leira R, Lizasoain I, Castillo J, Davalos A: The prediction of malignant cerebral infarction by molecular brain barrier disruption markers. Stroke 2005;36:1921-1926. 